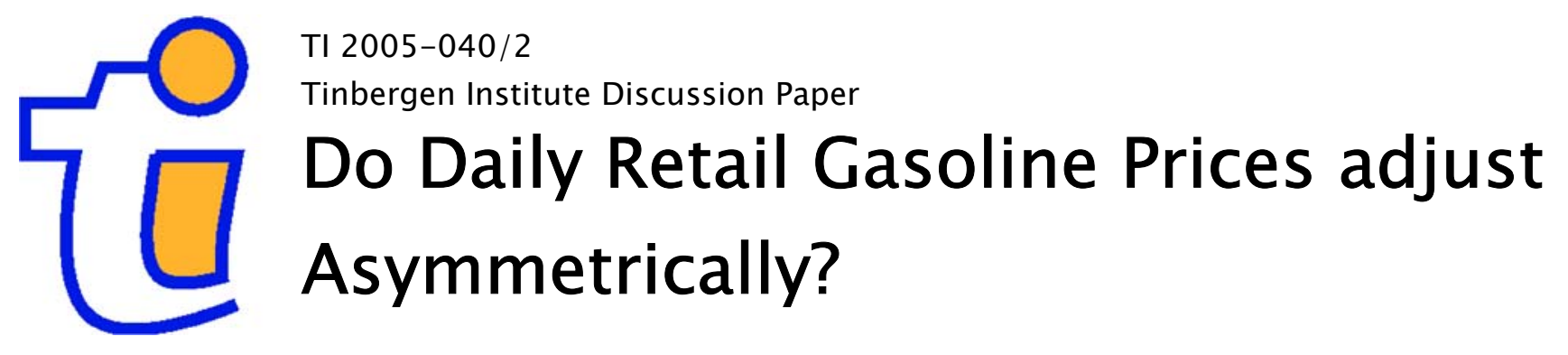

Leon Bettendorfl,2

Stephanie van der Geest ${ }^{l}$

Gerard Kuper ${ }^{3}$

\footnotetext{
${ }^{1}$ Erasmus Universiteit Rotterdam,

2 Tinbergen Institute,

3 University of Groningen.
} 


\section{Tinbergen Institute}

The Tinbergen Institute is the institute for economic research of the Erasmus Universiteit Rotterdam, Universiteit van Amsterdam, and Vrije Universiteit Amsterdam.

Tinbergen Institute Amsterdam

Roetersstraat 31

1018 WB Amsterdam

The Netherlands

Tel.: $\quad+31(0) 205513500$

Fax: $\quad+31(0) 205513555$

Tinbergen Institute Rotterdam

Burg. Oudlaan 50

3062 PA Rotterdam

The Netherlands

Tel.: $\quad+31(0) 104088900$

Fax: $\quad+31(0) 104089031$

Please send questions and/or remarks of nonscientific nature to driessen@tinbergen.nl.

Most TI discussion papers can be downloaded at http://www.tinbergen.nl. 


\title{
Do daily retail gasoline prices adjust asymmetrically?
}

\author{
L. Bettendorf*, S.A. van der Geest ${ }^{\dagger}$ and G.H. Kuper ${ }^{\ddagger \S}$
}

April 2005

\begin{abstract}
This paper analyzes adjustments in the Dutch retail gasoline prices. We estimate an error correction model on changes in the daily retail price for gasoline (taxes excluded) for the period 1996-2004 taking care of volatility clustering by estimating an EGARCH model. It turns out the volatility process is asymmetrical: an unexpected increase in the producer price has a larger effect on the variance of the producer price than an unexpected decrease.
\end{abstract}

We do not find strong evidence for amount asymmetry. However, there is a faster reaction to upward changes in spot prices than to downward changes in spot prices. This implies timing or pattern asymmetry. This asymmetry starts three days after the change in the spot price and lasts for four days.

Key words: Asymmetry; Retail gasoline prices, Volatility

JEL classification: D43; E31

\footnotetext{
${ }^{*}$ Erasmus University, P.O. Box 1738, 3000 DR Rotterdam, The Netherlands. Phone: +31-10-408-1808, E-mail: bettendorf@few.eur.nl.

${ }^{\dagger}$ Erasmus University, P.O. Box 1738, 3000 DR Rotterdam, The Netherlands. Phone: +31-10-408-8950, E-mail: vandergeest@few.eur.nl.

${ }^{\ddagger}$ Department of Economics, University of Groningen and SOM, P.O. Box 800, 9700 AV Groningen, The Netherlands. Phone: +31-50-363-3756, E-mail: g.h.kuper@eco.rug.nl.

${ }^{\S}$ The authors thank Dick van Dijk and participants of the IEE Brown Bag Seminar in Groningen for helpful comments on an earlier version of the paper. All errors are ours.
} 


\section{Introduction}

Starting by Bacon (1991), numerous studies have examined whether retail gasoline prices respond more quickly to upstream price increases than to decreases; see the overview in Bettendorf et al. (2003) or Eckert and West (2004). The findings on asymmetric price adjustments have been mixed. Estimations in most of these studies are based on weekly or even monthly data, whereas in reality gasoline prices are often adjusted more than once a week. ${ }^{1}$ Recent contributions have started to use high frequency data, showing that analyzing low frequency data might lead to an improper understanding of the pricing process when upstream prices are volatile.

Bettendorf et al. (2003) demonstrate that the findings on asymmetric pricing depend on the choice of the day for which weekly changes are calculated. Our paper extends their analysis by exploring the linkage between daily retail gasoline prices and spot prices for the Netherlands. Price changes on this highly concentrated retail market are initiated by the market leader, which are normally followed by the other firms. Since calm and turbulent periods of price changes seem to be clustered in time, Ordinary Least Squares (OLS) estimation of an ECM results in loss of statistical efficiency. An asymmetrical EGARCH model $^{2}$ (Nelson, 1991) is therefore estimated to accommodate for volatility clustering and for asymmetry in the volatility process. We find that retail prices respond more quickly to cost increases than to decreases. Unlike some recent contributions, this paper does not aim to identify the source of the asymmetry.

\footnotetext{
${ }^{1}$ For instance, the retail price in the Netherlands was adjusted two and three times a week during 22 and 3 weeks in 2004, respectively.

${ }^{2}$ EGARCH is short for Exponential Generalized AutoRegressive Conditional Heteroskedasticity. The GARCH process is a popular stochastic process which has been fairly successful in modeling financial time series (Engle, 2004).
} 
The paper is structured as follows. The next section summarizes the existing asymmetry studies that use daily data. Section 3 describes the Dutch retail market for gasoline. After the data are presented in Section 4, the model is introduced in Section 5. The estimation results of the ECM are discussed in Section 6. Findings are summarized in the last section.

\section{Literature}

With the growing availability of detailed time series on gasoline markets and the advances in high-frequency econometric analysis, several studies have recently tested the asymmetry hypothesis with daily observations. ${ }^{3}$ First, Bachmeier and Griffin (2003) question the robustness of the results of Borenstein et al. (1997). The latter study estimates a conventional ECM with weekly US data and finds an asymmetric response of gasoline spot prices to crude oil price changes. In contrast, Bachmeier and Griffin show that symmetry cannot be rejected when a similar specification is estimated with daily data.

Davis and Hamilton (2004) investigate the linkage between daily spot and wholesale gasoline prices set by 9 firms active in Philadelphia. They compare three types of models in estimating the probability of a price change. Following the Dixit menu-cost model, the gap between the current and the target price should be the dominant determinant in the pricing decision. Estimation of the derived specification results in implausible parameter values. Besides, this model is not consistent with the asymmetric response to positive and negative price gaps, found for 5 of the 9 firms with an atheoretical logit specification as

\footnotetext{
${ }^{3}$ Borenstein and Shepard (2002, section 3) provide an early example of the estimation with daily gasoline prices. The change in the price of a gasoline future contract is explained by the change in the price of a crude oil futures contract on the same day and on the two prior trading days. The pass through for these competitive markets is found to be symmetric but incomplete. The latter finding is attributed to production stickiness.
} 
well as with an autoregressive conditional duration model. In particular, when the actual price is below or above the target price by a small amount, a price increase is more likely found than a price decrease. In contrast, when the price gap is large (in absolute value), a wholesaler is more reluctant to raise prices than to lower them. Davis and Hamilton conclude that pricing decisions are more driven by strategic considerations about customers' and competitors' reactions than by explicit menu costs.

For several Canadian, US and Australian cities, retail gasoline prices are documented to exhibit a remarkable, saw-toothed pattern, even when wholesale prices are relatively stable; see Castanias and Johnson (1993) and Eckert (2003). Long periods in which prices decline gradually are succeeded by short periods with sharp price increases. These cycles can be explained by the duopoly model of Maskin and Tirole (1988). On the downward portion of the cycle, each firm undercuts prices to attract market share in the short run. When the price reaches a lower bound, one of the firms eventually restores the high price, which is quickly followed by its rivals and the cycle repeats. ${ }^{4}$ Eckert and West (2004) test this model by constructing an unbalanced panel of daily station-specific prices for 8 regions in the Vancouver area. Simple linear regressions show that large price increases occur almost exclusively on the days of the week for which demand is lowest. Furthermore, prices increase at the same day, while prices decrease at different speeds in different regions. Prices fall more rapidly when markets are less concentrated. They stress that these features cannot be identified when using a weekly survey at a small sample of stations. Notice that the finding that retail prices adjust differently over the cycle should not be confused with asymmetric responses to cost changes. In this case, price asymmetry does not arise from

\footnotetext{
${ }^{4}$ Note that these price cycles are not observed in the highly concentrated retail gasoline market in the Netherlands.
} 
collusive behaviour but, instead from relatively aggressive pricing. ${ }^{5}$

Finally, Lewis (2003) develops a theory that attributes asymmetric price adjustments to searching consumers with myopic expectations. Although the reference price search model is not yet tested on daily data, it might improve the understanding of price fluctuations. The crucial assumption is that expectations are based on prices observed in the past. When consumers observe a lower price than expected, a smaller fraction chooses to search. When the cost rises much higher than last period's price, firms have to set prices competitively to remain profitable. In contrast, when the cost falls well below last period's price, firms can keep high margins by reducing prices just enough to prevent consumers from searching. The model implies that prices do not react to cost changes during periods of high margin. Lewis (2003) tests the implications by means of a panel of weekly, station-specific prices from the San Diego area. An asymmetric ECM with one threshold is estimated, incorporating 4 sets of coefficients. Weeks for which the observed price exceeds the target price are assigned to the high margin regime. The low margin regime is identified by negative long run residuals. Next, the effects of cost increases and decreases are allowed to differ in each regime. Evidence for asymmetric responses to cost changes is found but the size of the margin seems a more important determinant of the adjustment speed. Lewis (2003) also argues that the reference price search model seems more consistent with observed patterns than two alternative explanations, suggested by Borenstein et al. (1997). ${ }^{6}$ These alternatives are a collusion model and a standard search model. ${ }^{7}$

\footnotetext{
${ }^{5}$ Noel (2004) examines similar cycles found with a panel of twice-daily retail prices for 22 service stations in Toronto. Results of a Markov switching regression with two regimes are consistent with predictions of the Maskin and Tirole (1988) theory. Undercutting phases, lasting on average 6.4 days, are found to be more likely triggered by small independents. Rounds of price increases take only half a day and are mostly initiated by large firms.

${ }^{6}$ They propose production and inventory adjustment lags as a third alternative.

${ }^{7}$ This search model assumes that consumers search less when facing highly variable costs. With large
} 


\section{The Dutch retail market for gasoline}

The Dutch gasoline market can be characterized as a strong oligopoly (see Canoy and Onderstal, 2003). Several features support this observation. First, the market is dominated by five integrated oil companies: Shell, BP/Mobil, Exxon, Texaco and Total/Fina/Elf. As can be seen in Figure 1, these companies sell approximately $80 \%$ of the gasoline sold, with Shell having by far the largest market share (30\%). The independent retailers only account for $16 \%$ of the total volume. Along the highways the market is even more concentrated as branded filling stations are mainly located at these prime locations, whereas non-branded filling stations almost never are located along the highways. Concentration on the Dutch market is much higher than in other European countries.

Second, entry barriers are high. To enter the retail gasoline market a license is required and new locations are scarce. As a result of restrictive planning, strict environmental standards and a reserved permission policy by national and local governments only a very few firms were able to enter the market. In particular along the highways the government has rarely issued licenses to new players. New licenses (with an unlimited time period) were mainly issued to incumbents who already had a strong position in the market.

Third, price formation is very transparent for petrol firms. Since the market leader Shell publicly announces changes in its recommended retail price on its website, competing oil companies can easily monitor and follow Shell's pricing policy. Although there is no clear evidence whether the oil companies do coordinate their prices, the Netherlands Competifluctuations of wholesale prices, it is costly for a consumer to check whether an observed price change is really due to a cost change, that is followed by the other suppliers. This gives the firms market power to adjust prices more slowly after a cost decrease. 
Figure 1: Volume shares in 2000 (source Bettendorf et al., 2003)

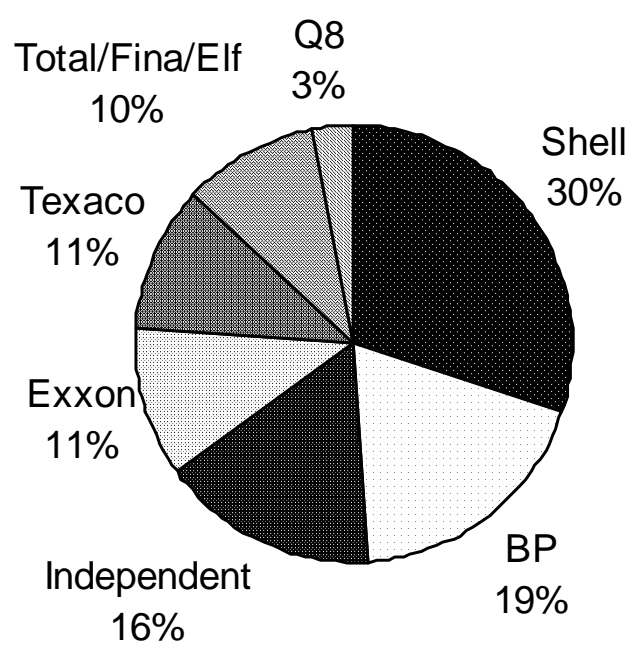

tion Authority (NMa) has concluded that the differences between the recommended prices of the various firms are marginal (NMa, 2001). Fourth, the margin on gasoline prices is higher than in other European countries. This higher margin is only partially explained by higher costs in the Netherlands such as wage and environmental costs (see European Commission, 1999).

Finally, it is argued that competition is restricted through a system of vertical agreements between oil companies and filling station owners. Oil companies financially support an affiliated filling station when faced with a price war in the neighbourhood, unless the station itself has initiated a price reduction. As a result, a station owner has less incentive to cut the price, knowing that price supports allow his rivals to follow the reduction immediately. The NMa no longer intends to prohibit these support systems because the 
evidence on the implications for retail prices is insufficient (NMa, 2003).

Summarizing, characteristics of the Dutch gasoline market seem to limit price competition. However, recently some favourable developments are observed. NMa (2004) concludes that competition has increased on local and regional roads due to the increasing number of unmanned and independent filling stations. Developments are going much more slowly on the motorway network. To reduce market concentration on the primary roads, the government has started to re-allocate 10 licenses each year over a period of 21 years using auctions. The past two auctions have resulted in few changes, for example only one new player (Samba Oil) has entered the market.

\section{The data}

Before analyzing the link between daily retail gasoline prices and spot prices we describe the data we use. We analyze the data and indicate why we have to use ARCH models. In the next section we test for stationarity and cointegration in order to arrive at the proper specification of the model.

Daily data are collected for the period 2 January 1996 through 7 December 2004. Prices are expressed in euros per litre. ${ }^{8}$

\footnotetext{
${ }^{8}$ This dataset differs from the one used in Bettendorf et al. (2003) in four ways. First, this dataset contains daily data instead of weekly data. Second, variables are not expressed in guilders but in euros. Third, we use the spot price for regular instead of premium gasoline. Finally, the dataset is extended with the years 2002-2004. Only the first difference is fundamental for the findings of this study.
} 


\section{Sources}

Retail prices $(R P)$ of unleaded gasoline (Euro95) are taken from the website of Shell. ${ }^{9}$ This is the price which market leader Shell recommends to its filling stations. Price changes are decided by Shell's pricing committee at $11.00 \mathrm{AM}$ and implemented at $0.00 \mathrm{AM}$ the next day (Shell, 2001). On Sundays the retail price is never adjusted, probably because both the Rotterdam spot market and the financial markets are closed during weekends. For that reason Sundays are excluded from the dataset. Prices often do change on Saturdays to incorporate Friday's closing spot prices and exchange rates.

We use the Rotterdam spot price (WP) for regular unleaded gasoline as the input cost of Euro95. ${ }^{10}$ These spot prices are published on the website of the US Energy Information Administration. ${ }^{11}$ Where observations are missing (in case of a holiday), the price of the previous day is used. To convert the dollar price into euros per litre we use the dollar/euro exchange rate as collected by Datastream. For the pre-euro years 1996-2001 we multiply the dollar/guilder exchange rate with the official exchange rate of 1 euro $=$ 2.20371 guilders.

The retail price data include consumer taxes. In the sample period the value added tax ( $V A T)$ on gasoline has changed from $17.5 \%$ to $19.0 \%$ on 1 January 2001 . Besides VAT, excise taxes $(E X C)$ are levied. ${ }^{12}$ Data on excise taxes are obtained from Statistics Nether-

\footnotetext{
${ }^{9}$ www.shell.nl

${ }^{10}$ The technical details of the regular unleaded gasoline are ARA barge, 91 RON, 82.5 MON, 50ppm max sulfur. The prices quoted are the average of the "bid" and "offer" prices at the end of the trading day.

${ }^{11}$ www.eia.doe.gov/oil-gas/petroleum/info-glance/gasoline.html

${ }^{12}$ VAT is also imposed on excise taxes.
} 
Figure 2: Changes in excises $E X C_{t}$ and changes in retail $R P E_{t}$ and spot prices $W P_{t}$

$\square \mathrm{D}(\mathrm{RPE}) \square \mathrm{D}(\mathrm{WP}) \square \mathrm{D}(\mathrm{EXC})$

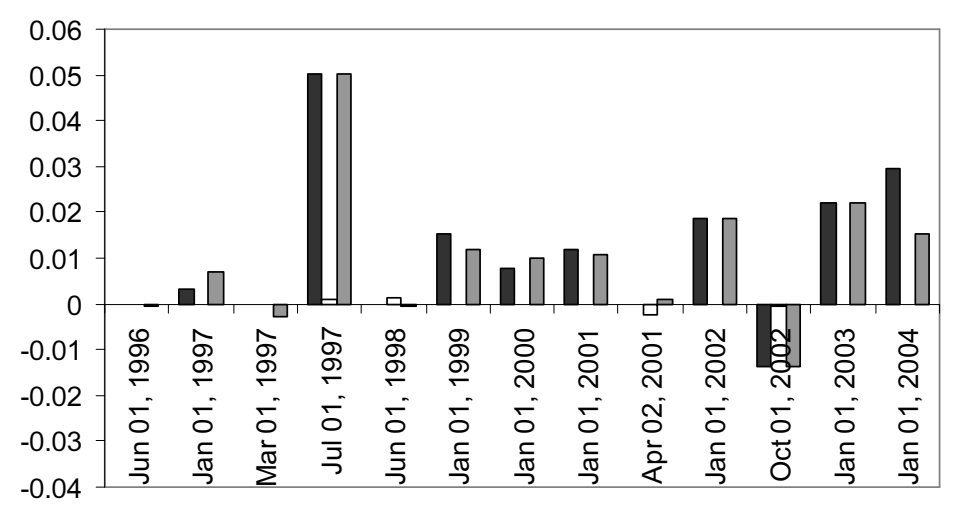

lands. ${ }^{13}$ In the sample period there have been only 13 changes in excise taxes on unleaded gasoline (4 negative, 9 positive). The excises taxes underwent their most important change on 1 July 1997: from 0.528 to 0.578 euros per litre. Between 1 October 2002 and 1 January 2003 there was a large short-lived drop in excises from 0.630 to 0.616 euros per litre. Changes in excise taxes are usually passed on to the retail price immediately (see Figure 2), where $R P E_{t}$ is defined as $R P E_{t}=R P_{t} /\left(1+V A T_{t}\right)$. As we do not want our tests to be affected by the changes in excise taxes we from now on focus on producer price, defined as $P P_{t}=R P E_{t}-E X C_{t}$.

\section{Descriptive statistics}

The levels of the producer price and the spot price are highly correlated as the correlation coefficient of both series equals 0.988 (see Table 1). First differences are however not correlated. ${ }^{14}$ Figure 3 illustrates that both prices follow each other closely.

\footnotetext{
${ }^{13}$ statline.cbs.nl, Table "Heffingen (totaal) op energiedragers".

${ }^{14}$ Prefix $\Delta$ denotes the backward difference $\Delta X_{t}=X_{t}-X_{t-1}$
} 
Table 1: Correlations

\begin{tabular}{lcccc}
\hline & $P P_{t}$ & $W P_{t}$ & $\Delta P P_{t}$ & $\Delta W P_{t}$ \\
\hline \hline$P P_{t}$ & 1.000 & & & \\
$W P_{t}$ & 0.988 & 1.000 & & \\
$\Delta P P_{t}$ & 0.025 & 0.035 & 1.000 & \\
$\Delta W P_{t}$ & -0.039 & 0.029 & 0.021 & 1.000 \\
\hline
\end{tabular}

Figure 3: Time series (daily data for the period 1996-2004) of producer prices $P P_{t}$ and spot prices $W P_{t}$

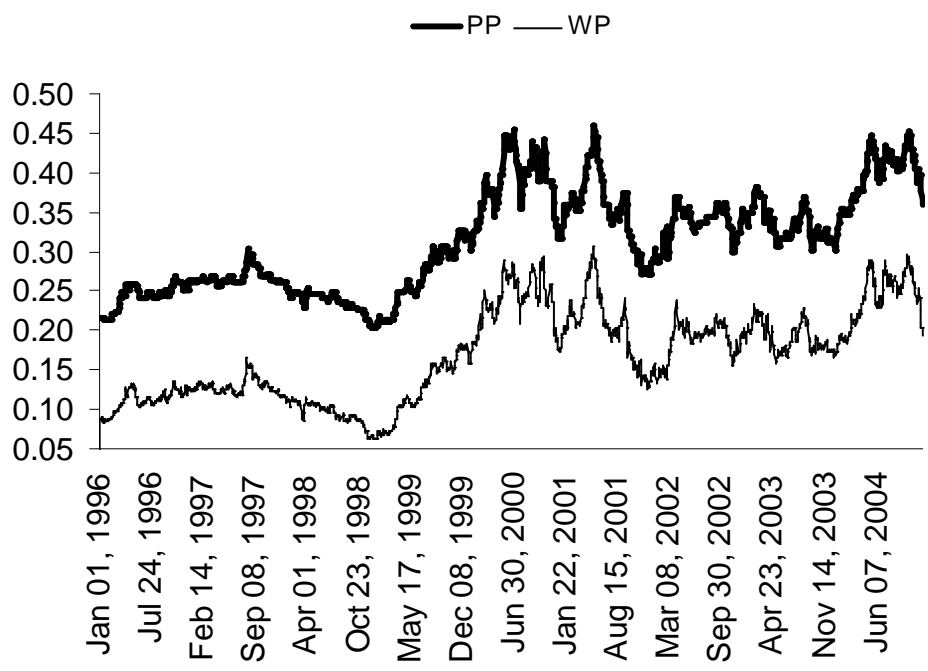


Table 2: Number of adjustments of $\Delta P P_{t}$, categorized by values of $\Delta P P_{t} \neq 0$ and $\Delta W P_{t}$. Listed are the mean and the number of observations in each category, respectively

\begin{tabular}{|c|c|c|c|c|}
\hline & \multicolumn{3}{|c|}{$\overline{\Delta W P_{t}}$} \\
\hline & & {$[-0.02,0)$} & {$[0,0.02)$} & All \\
\hline & {$[-0.06,-0.04)$} & $\overline{\mathrm{NA}}$ & -0.042 & $\begin{array}{l}-0.042 \\
\end{array}$ \\
\hline & & 0 & 1 & 1 \\
\hline & {$[-0.04,-0.02)$} & NA & NA & NA \\
\hline & & 0 & 0 & 0 \\
\hline \multirow{8}{*}{$\Delta P P_{t}$} & {$[-0.02,0)$} & -0.008 & -0.008 & -0.008 \\
\hline & & 87 & 146 & 233 \\
\hline & $(0,0.02)$ & 0.009 & 0.007 & 0.008 \\
\hline & & 88 & 165 & 253 \\
\hline & {$[0.02,0.04)$} & NA & 0.029 & 0.029 \\
\hline & & 0 & 1 & 1 \\
\hline & All & 0.000 & 0.000 & 0.000 \\
\hline & & 175 & 313 & 488 \\
\hline
\end{tabular}

Table 2 shows the number of producer price adjustments. There have been 488 changes in the producer price. This implies that, on average, there is about one change in the producer price per week. There have been 254 (52\%) increases and 234 (48\%)decreases. In $88(18 \%)$ cases the producer price rose while the spot price fell. On the other hand there are 147 (30\%) days in which producer price fell despite a rise in the spot price. In only $87(18 \%)$ cases both the producer price and the spot price decreased, whereas in 166 (34\%) cases both prices rose.

\section{Volatility clustering}

Table 3 shows significant autocorrelations of $\Delta P P_{t}$ and $\left[\Delta P P_{t}\right]^{2}$ indicating volatility clustering (autocorrelations larger than 0.038 in absolute values would be significant at a $5 \%$ level). Volatility clustering is also indicated in Figures 4 and 5. 
Table 3: Autocorrelations of first differences and squared first differences in $P P_{t}$

\begin{tabular}{rrr}
\hline & First differences & Squared first differences \\
\hline \hline 1 & 0.047 & -0.033 \\
2 & 0.096 & 0.062 \\
3 & 0.075 & 0.030 \\
4 & 0.057 & 0.053 \\
5 & 0.029 & 0.011 \\
6 & 0.019 & 0.022 \\
7 & -0.004 & 0.037 \\
8 & -0.003 & 0.022 \\
9 & -0.003 & 0.005 \\
10 & 0.004 & 0.035 \\
\hline
\end{tabular}

Two standard error bounds are computed

as $\pm 2 / \sqrt{T}= \pm 0.038$, with $T=2797$

Figure 4: Level and differences in producer price of gasoline $P P_{t}$

$-P P \_D(P P)$ (right)

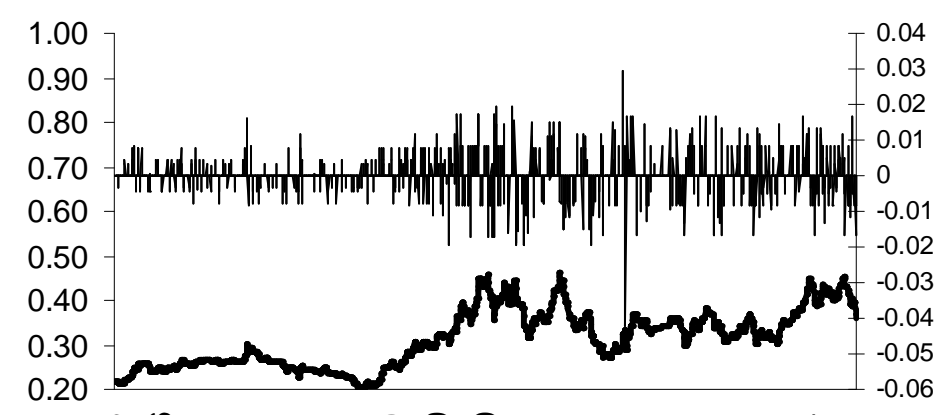

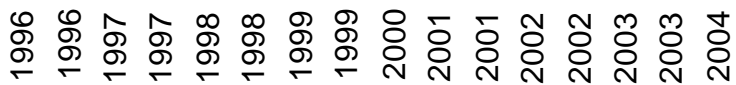

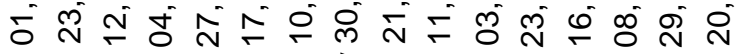

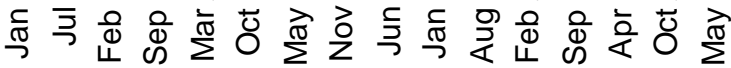


Figure 5: Level and differences in gasoline spot prices $W P_{t}$

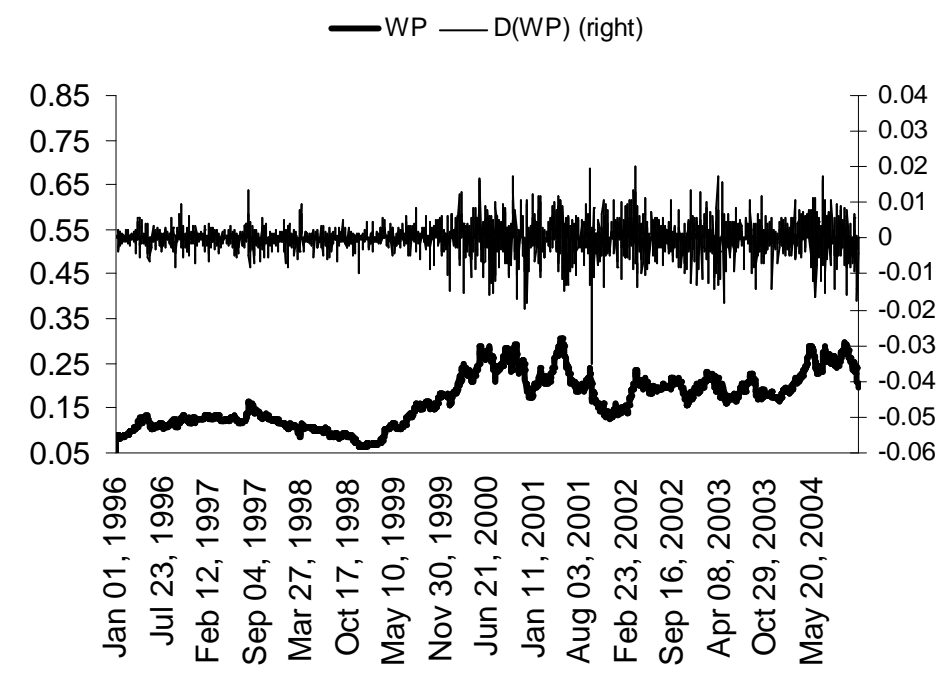

In Figures 4 and 5 prices are shown on the left axis and daily changes of prices are shown on the right axis. These figures show an increase in prices in the second halve of the sample. Moreover, price changes are becoming more volatile and the amplitude of the prices changes is changing as well. The magnitude of the price change is small for extended periods and then low for extended periods. This is what has been called volatility clustering and is the effect ARCH models are designed to measure. ${ }^{15}$

Assuming, as is done in OLS regressions, that the variance of the error term is constant results in loss of statistical efficiency (Engle 1982, Bollerslev et al. 1994, for an overview see Engle 2004).

\footnotetext{
${ }^{15}$ Volatility clustering is still present if we include time dummies in the model for the period 1999-2004.
} 


\section{Model specification}

Most models in this literature are error correction models (ECM). Before estimating an ECM we have to test stationarity and cointegration. If producer prices and spot prices are integrated of order one, and if these prices are cointegrated then an ECM is applicable. Before presenting any estimation results we first describe the outcomes of the various stationarity and cointegration tests.

\section{Stationarity and cointegration}

We use the Augmented Dickey-Fuller (ADF) unit root tests as well as the Phillips-Perron (P-P) test to test for stationarity. The P-P test has been shown to be more powerful in the presence of heteroscedasticity and serial correlation under a wide range of circumstances (Phillips and Perron, 1988). Both tests in Table 4 clearly indicate that the producer price $P P_{t}$ and the spot price $W P_{t}$ are $\mathrm{I}(1)$, i.e. the prices are stationary after taking first differences. The null hypothesis that $P P_{t}$ has a unit root is not rejected ( $p$-value is 0.211 ), whereas the null that $\Delta P P_{t}$ has a unit root is rejected ( $p$-value is 0.000$)$. The same conclusion holds for $W P_{t}$. The null that $W P_{t}$ has a unit root is not rejected ( $p$-value is 0.224). First differencing $W P_{t}$ clearly rejects the null of a unit root in $\Delta W P_{t}$ ( $p$-value is $0.000)$.

We assume that our prices share a uniform volatility process and that cointegration is robust with respect to ARCH innovations. ${ }^{16}$ So, we use the familiar Johansen cointegration

\footnotetext{
${ }^{16}$ See Rahbek et al., 2002. There is some evidence for stock market indices sharing a uniform volatility process (see Engle and Kozicki, 1993). An alternative cointegration test with GARCH effects is provided by Gannon (1996).
} 
Table 4: Augmented Dickey-Fuller and Phillips-Perron unit root tests

\begin{tabular}{lrrrr}
\hline & $P P_{t}$ & $\Delta P P_{t}$ & $W P_{t}$ & $\Delta W P_{t}$ \\
\hline \hline \multicolumn{1}{c}{ Augmented Dickey-Fuller test } & & & & \\
Exogenous & constant & none & constant & none \\
Lag length (SIC) & 3 & 2 & 1 & 0 \\
ADF test statistic & -2.187 & -26.218 & -2.153 & -49.114 \\
Critical values 5\% level & -2.862 & -1.941 & -2.862 & -1.941 \\
$p$-value* & 0.211 & 0.000 & 0.224 & 0.000 \\
Observations & 2794 & 2794 & 2795 & 2795 \\
Null of unit root & not rejected & rejected & not rejected & rejected \\
\hline Phillips-Perron test & & & & \\
Exogenous & constant & none & constant & none \\
Bandwidth & 17 & 16 & 11 & 9 \\
P-P test statistic & -2.183 & -51.487 & -2.236 & -49.366 \\
Critical values 5\% level & -2.862 & -1.941 & -2.862 & -1.941 \\
$p$-value* & 0.213 & 0.000 & 0.193 & 0.000 \\
Observations & 2794 & 2794 & 2795 & 2795 \\
Null of unit root & not rejected & rejected & not rejected & rejected \\
\hline *MacKinnon (1996) one-sided $p$-values & & & \\
\hline
\end{tabular}

Table 5: Johansen cointegration test

\begin{tabular}{|c|c|c|c|c|}
\hline \multicolumn{5}{|c|}{ Series $\quad R P E_{t}, E X C_{t} W P_{t}$} \\
\hline Trend assumption & "no determi & trend & & \\
\hline Lags & 4 & & & \\
\hline Observations & 2792 & & & \\
\hline \multicolumn{5}{|c|}{ Unrestricted cointegration rank test (trace) } \\
\hline Hypothesized no. of $\mathrm{CE}(\mathrm{s})$ & eigenvalue & trace statistic & $5 \%$ critical value & $p$-value** \\
\hline None * & 0.073 & 224.500 & 35.193 & 0.000 \\
\hline At most 1 & 0.003 & 13.743 & 20.262 & 0.308 \\
\hline At most 2 & 0.002 & 4.558 & 9.165 & 0.335 \\
\hline \multicolumn{5}{|c|}{ Unrestricted cointegration rank test (maximum eigenvalue) } \\
\hline Hypothesized no. of $\mathrm{CE}(\mathrm{s})$ & eigenvalue & -eigen statistic & $5 \%$ critical value & $p$-value ${ }^{* *}$ \\
\hline None ${ }^{*}$ & 0.073 & 210.757 & 22.300 & 0.000 \\
\hline At most 1 & 0.003 & 9.186 & 15.892 & 0.414 \\
\hline At most 2 & 0.002 & 4.558 & 9.165 & 0.335 \\
\hline
\end{tabular}


test. The Johansen cointegration test in Table 5 indicates 1 cointegrating equation at the 0.05 level (both the Trace test and the Max-eigenvalue test yield consistent results). This implies that the relationship between cointegrated series can be considered to be generated by an error correction model (Granger and Weiss, 1983): a system not in equilibrium has a tendency to converge to equilibrium in the long run. This implies that the retail price $R P E_{t}$, excises $E X C_{t}$ and the spot price $W P_{t}$ cannot drift apart in the long run.

\section{Error correction model}

The model consists of regressors that explain short run dynamics of gasoline retail prices and the error correction part (OLS errors from the levels equation). The short run allows for asymmetric adjustment.

The ECM is estimated in two rounds following Engle and Granger (1987). First, we estimate the long-run equation using OLS:

$$
R P E_{t}=\mu_{0}+\mu_{1} W P_{t}+\mu_{2} E X C_{t}+\eta_{t}
$$

The specification can be derived from the maximization of static profits by an oligopolist (see Bettendorf et al., 2003). Under the assumption that marginal costs are independent of the output level and that the mark-up ratio is constant, the parameters $\mu_{2}$ and $\mu_{1} / \mu_{2}$ are interpreted as the mark-up ratio and the effect of spot price changes in costs, respectively. ${ }^{17}$

Second, we capture the short-run dynamics including asymmetries in first differences as:

\footnotetext{
${ }^{17}$ This price setting relation requires the model to be estimated in absolute price changes and not in rates of growth. Moreover, this is the common procedure in the gasoline asymmetry literature which makes it easier to compare the results.
} 


$$
\begin{aligned}
\Delta\left(P P_{t}\right)= & \sum_{i=0}^{n} \lambda_{i}^{+} \Delta W P_{t-i}^{+}+\sum_{j=0}^{m} \lambda_{j}^{-} \Delta W P_{t-j}^{-}+ \\
& \omega^{+} R E S_{t-1}^{+}+\omega^{-} R E S_{t-1}^{-}+\epsilon_{t}
\end{aligned}
$$

where RES are the residuals from Equation (1). The superscripts + and - refer to the positive part and negative part of the time series, so that

$$
X_{t}^{+}=\left\{\begin{array}{cc}
X_{t} & \text { if } X_{t}>0 \\
0 & \text { if } X_{t}<0
\end{array}\right.
$$

and

$$
X_{t}^{-}=\left\{\begin{array}{cc}
0 & \text { if } X_{t}>0 \\
X_{t} & \text { if } X_{t}<0
\end{array}\right.
$$

The first two terms in Equation (2) are current and lagged spot price increases and decreases, respectively. The number of lags for decreases $m$ and increases $n$ is determined by minimizing the Akaike Information Criterion. Also the adjustment process toward the long run can be asymmetrical.

\section{EGARCH specification}

ARCH LM-tests of OLS estimates of Equation (2) (not reported here) indicate that volatility is serially correlated over time $(p$-value is 0.024$) .{ }^{18}$ Defining $\epsilon_{t}^{2}$ as the variance of the error term $\epsilon_{t}$ in Equation (2), also known as the mean equation, one can

\footnotetext{
${ }^{18}$ This implies that OLS estimates are not efficient and that neglecting volatility clustering affects the tests for asymmetry.
} 
test whether the conditional variance $\sigma_{t}^{2}$, is affected by conditional variances $p$ periods in the past $\left(\sigma_{t-j}^{2}, j=1, \ldots, p\right)$ as well as by $q$ lags of the unconditional variance terms $\left(\epsilon_{t-i}^{2}, i=1, \ldots, q\right)$. This is done by determining the significance of the parameters in a GARCH model.

To allow for asymmetry in the volatility process we use the Exponential GARCH (EGARCH) model (Nelson 1991):

$$
\ln \sigma_{t}^{2}=\alpha_{0}+\sum_{i=1}^{q} \alpha_{i}\left|\frac{\epsilon_{t-i}}{\sigma_{t-i}}\right|+\sum_{j=1}^{p} \beta_{j} \ln \sigma_{t-j}^{2}+\sum_{k=1}^{r} \gamma_{k}\left(\frac{\epsilon_{t-k}}{\sigma_{t-k}}\right)
$$

In EGARCH, the natural $\log$ of the conditional variance $\ln \sigma_{t}^{2}$, is affected by the natural $\log$ of conditional variances $p$ periods in the past $\left(\ln \sigma_{t-j}^{2}, j=1, \ldots, p\right)$ as well as by $q$ lags of the unconditional normalized standard deviations in absolute values $\left(\left|\epsilon_{t-i} / \sigma_{t-i}\right|, i=\right.$ $1, \ldots, q)$. Asymmetry is introduced by including $r$ lags of the unconditional normalized standard deviations $\left(\epsilon_{t-k} / \sigma_{t-k}, k=1, \ldots, r\right)$. Unlike GARCH and threshold GARCH, the $\log$ specification does not require non-negativity constraints on the parameters to ensure positive conditional variances. However, restrictions on $\beta_{j}$ are required to ensure stationarity. If the coefficients $\gamma_{k} \neq 0$, the response of volatility to shocks is asymmetrical. For instance if $p=q=r=1$ : negative shocks have an impact of $\alpha_{1}-\gamma_{1}$ on the log of the conditional variance and positive shocks have an effect of $\alpha_{1}+\gamma_{1}$. Stationarity of $\operatorname{EGARCH}(1,1)$ requires $\left|\beta_{1}\right|<1 .{ }^{19}$

Summarizing, GARCH models consist of a "mean equation," which in our case is the ECM presented in Equation (2). The second equation describes the "conditional variance" which

\footnotetext{
${ }^{19}$ It should be noted that threshold GARCH (TGARCH) models produce similar results.
} 
Table 6: Long-run OLS results

\begin{tabular}{lrr}
\hline$R P E_{t}=\mu_{0}+\mu_{1} W P_{t}+\mu_{2} E X C_{t}+\eta_{t}$ & \\
& Coefficient & $(t$-value $)$ \\
\hline \hline$\mu_{0}$ & 0.081 & $(25.829)$ \\
$\mu_{1}$ & 1.045 & $(258.963)$ \\
$\mu_{2}$ & 1.093 & $(183.951)$ \\
Observations & 2797 & \\
Adjusted $R^{2}$ & 0.991 & \\
S.E. of regression & 0.009 & \\
$F$-statistic $(p$-value $)$ & 146011.7 & $(0.000)$ \\
Durbin-Watson & 0.360 & \\
Wald tests & $F$-statistic & $(p$-value $)$ \\
$H_{0}: \mu_{2}=1(\mathrm{df}=2794)$ & 245.921 & $(0.000)$ \\
$H_{0}: \mu_{1} / \mu_{2}=1(\mathrm{df}=2794)$ & 29.523 & $(0.000)$ \\
\hline
\end{tabular}

in our case is an $\operatorname{EGARCH}(p, q)$ model.

We have to determine the number of ARCH and GARCH terms (using $z$-tests). In all models presented below the EGARCH(1,1) model explains most of the variability of the changes in producer prices. The $z$-test for significance and the Akaike Information Criterion are used to determine the number of periods with rising and falling spot prices.

\section{$6 \quad$ Estimation results}

The ECM is estimated in two rounds. First, we estimate the Equation (1) using OLS. These results are unaffected by volatility clustering (asymptotically). Table 6 indicates that the mark-up $\left(\mu_{2}=1.093\right)$ is significantly bigger than $1(\mathrm{p}=0.000)$ and the effect of spot price changes in costs $\left(\mu_{1} / \mu_{2}=0.956\right)$ is significantly smaller than $1(\mathrm{p}=0.000)$.

In the second round we include the lagged long-run residuals in the short-run equation. We 
estimate Equation (2) with and without asymmetry in the adjustment towards the long run to find evidence for asymmetries. There are various types of asymmetries (see Geweke, 2004). If the retail price and the spot price are cointegrated, these variables will not drift apart in the long run. Hence, there is no amount asymmetry in the long run, but perhaps there is amount asymmetry in the short run. We define short-run amount asymmetry if $\sum \lambda_{i}^{+} \neq \sum \lambda_{j}^{-}$. Timing or pattern asymmetry refers to differences in estimates of $\lambda_{j}^{+}$and $\lambda_{j}^{-}$at the same lags $j$. There is another type of asymmetry, which has to do with the speed of adjustment towards the long run. Adjustment asymmetry is present if $\omega^{+} \neq \omega^{-}$. Finally, the effects of volatility to shocks can be asymmetrical. This shock asymmetry is present if in the variance equation $\gamma_{k} \neq 0$.

Before discussing the results and testing the various types of asymmetry we note that the model in Table 7 is an EGARCH(1,1) model with standard normal distributed errors. The ARCH-LM test in Table 7 indicates that the EGARCH $(1,1)$ model properly accounts for heteroscedasticity and that the volatility process is stationary. The Durbin-Watson statistic indicates that there is no autocorrelation.

Table 7 yields the following conclusions:

1. The volatility process is asymmetrical. Since $\alpha_{1}>\gamma_{1}>0$ and $0<\beta_{1}<1$, shocks increase volatility and positive shocks have a larger effect on volatility than negative shocks of the same size. An unexpected increase in the producer price has a larger effect on the variance of the producer price than an unexpected drop in the producer price. This evidence of shock asymmetry might have a search cost explanation. Consumers who observe a turbulent world oil market are more reluctant to start a costly 
Table 7: EGARCH(1,1) estimation results

\begin{tabular}{|c|c|c|c|c|}
\hline \multicolumn{5}{|c|}{$\begin{array}{l}\Delta P P_{t}=\sum_{i=0}^{n} \lambda_{i}^{+} \Delta W P_{t-i}^{+}+\sum_{j=0}^{m} \lambda_{j}^{-} \Delta W P_{t-j}^{-}+\omega^{+} R E S_{t-1}^{+}+\omega^{-} R E S_{t-1}^{-}+\epsilon_{t} \\
\text { with } \ln \sigma_{t}^{2}=\alpha_{0}+\sum_{i=1}^{q} \alpha_{i}\left|\frac{\epsilon_{t-i}}{\sigma_{t-i}}\right|+\sum_{j=1}^{p} \beta_{j} \ln \sigma_{t-j}^{2}+\sum_{k=1}^{r} \gamma_{k}\left(\frac{\epsilon_{t-k}}{\sigma_{t-k}}\right)\end{array}$} \\
\hline & Coefficient & ( $z$-value) & Coefficient & ( $z$-value) \\
\hline$\overline{\overline{\lambda_{0}^{+}}}$ & -0.008 & 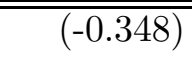 & "-0.008 & 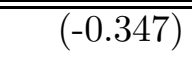 \\
\hline$\lambda_{1}^{+}$ & -0.035 & $(-1.430)$ & -0.035 & $(-1.487)$ \\
\hline$\lambda_{2}^{+}$ & 0.197 & $(8.991)$ & 0.197 & $(9.593)$ \\
\hline$\lambda_{3}^{+}$ & 0.223 & $(10.651)$ & 0.223 & $(10.901)$ \\
\hline$\lambda_{4}^{+}$ & 0.075 & $(3.461)$ & 0.075 & $(3.531)$ \\
\hline$\lambda_{5}^{+}$ & 0.080 & $(3.113)$ & 0.080 & $(3.213)$ \\
\hline$\lambda_{6}^{+}$ & 0.109 & $(4.452)$ & 0.109 & $(4.450)$ \\
\hline$\lambda_{7}^{+}$ & 0.024 & $(0.869)$ & 0.024 & $(0.869)$ \\
\hline$\lambda_{0}^{-}$ & 0.007 & $(0.283)$ & 0.007 & $(0.284)$ \\
\hline$\lambda_{1}^{-}$ & -0.052 & $(-2.126)$ & -0.052 & $(-2.158)$ \\
\hline$\lambda_{2}^{-}$ & 0.176 & $(8.206)$ & 0.176 & $(8.388)$ \\
\hline$\lambda_{3}^{-}$ & 0.125 & $(6.396)$ & 0.125 & $(6.485)$ \\
\hline$\lambda_{4}^{-}$ & 0.093 & $(3.904)$ & 0.093 & $(3.932)$ \\
\hline$\lambda_{5}^{-}$ & 0.079 & $(3.104)$ & 0.079 & $(3.122)$ \\
\hline$\lambda_{6}^{-}$ & 0.060 & $(2.132)$ & 0.060 & $(2.129)$ \\
\hline$\lambda_{7}^{-}$ & 0.079 & $(3.478)$ & 0.079 & $(3.468)$ \\
\hline$\lambda_{8}^{-}$ & 0.042 & $(1.646)$ & 0.042 & $(1.676)$ \\
\hline$\omega^{+}$ & -0.110 & $(-10.676)$ & & \\
\hline$\omega^{-}$ & -0.110 & $(-9.625)$ & & \\
\hline$\omega$ & & & -0.110 & $(-17.809)$ \\
\hline$\alpha_{0}$ & -0.090 & $(-10.354)$ & -0.090 & $(-10.345)$ \\
\hline$\alpha_{1}$ & 0.078 & $(18.798)$ & 0.079 & $(18.809)$ \\
\hline$\beta_{1}$ & 0.997 & $(1511.600)$ & 0.997 & $(1504.503)$ \\
\hline$\gamma_{1}$ & 0.016 & $(4.119)$ & 0.016 & $(5.420)$ \\
\hline Observations & 2788 & & 2788 & \\
\hline Adjusted $R^{2}$ & 0.272 & & 0.273 & \\
\hline S.E. of regression & 0.003 & & 0.003 & \\
\hline Durbin-Watson & 2.282 & & 2.281 & \\
\hline ARCH LM-test ( $p$-value) & 0.341 & $(0.559)$ & 0.339 & $(0.560)$ \\
\hline Wald tests & $F$-statistic & ( $p$-value $)$ & $F$-statistic & ( $p$-value) \\
\hline$H_{0}: \beta_{1} \geq 1 \mathrm{v} H_{1}: \beta_{1}<1$ & 26.142 & $(0.000)$ & 26.179 & $(0.000)$ \\
\hline 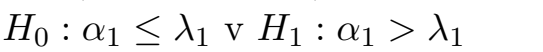 & 110.571 & $(0.000)$ & 134.585 & $(0.000)$ \\
\hline$H_{0}: \lambda_{i}^{+}=\lambda_{i}^{-} \forall i \vee H_{1}: \lambda_{i}^{+} \neq \lambda_{i}^{-}$ & 1.750 & $(0.073)$ & 2.336 & $(0.013)$ \\
\hline$H_{0}: \lambda_{\Sigma}^{+}=\lambda_{\Sigma}^{-}$v $H_{1}: \lambda_{\Sigma}^{+} \neq \lambda_{\Sigma}^{-}$ & 0.667 & $(0.414)$ & 2.373 & $(0.124)$ \\
\hline$H_{0}: \omega^{+}=\omega^{-}$ $H_{1}: \omega^{+} \neq \omega^{-}$ & 0.001 & $(0.972)$ & & \\
\hline
\end{tabular}


price comparison when faced with a price change. Firms can benefit from reduced search incentives by adjusting retail prices more rapidly upwards than downwards in periods with uncertain costs.

2. The adjustment parameter is about -0.11 and highly significant which implies that it takes about $0.5 / 0.11=4.5$ days to close half the gap between the current state and the long-run equilibrium. The final test reported in Table 7 does not reject to null of adjustment symmetry.

Because of the last conclusion, we focus on the second model in Table 7 in which the adjustment speed is symmetrical. This leads to the following conclusions:

3. For most lags $j$ spot price increases and spot price decreases affect the producer price significantly. Contemporaneous spot prices changes are not significant. Oneday lagged spot price decreases increase the producer price (this is what is expected from Table 2 above).

4. The number of lags for spot price increases and spot price decreases, 8 and 9 days respectively, is determined by minimizing the Akaike Information Criterion. So there is a faster reaction to upward changes in spot prices than to downward changes in spot prices. Simultaneous testing equality of all parameters for the same lags (the third reported Wald test in Table 7) rejects the null of equality. This implies that for at least one lag the parameters differ significantly. The Wald test reveals that the parameters for changes are significantly bigger for the third lag (the null of $\lambda_{3}^{+}=\lambda_{3}^{-}$ is rejected at $5 \%$ ). This implies timing or pattern asymmetry three days after the 
change in the spot price.

5. Already from Table 5 we concluded that there is no amount asymmetry in the long run. From Table 7 we conclude that the sum of all upward price change parameters is not significantly different from the sum of all downward price change parameters (two-sided test) at 5\%. The difference between the sum of upward and downward parameters $\left(\lambda_{\Sigma}^{+}-\lambda_{\Sigma}^{-}\right)$equals 0.057 . The table reports two-sided tests. However, for a one-sided test, the appropriate probability is one-half that reported in the table. So, if we would test $H_{0}: \lambda_{\Sigma}^{+} \leq \lambda_{\Sigma}^{-} \mathrm{\vee} H_{1}: \lambda_{\Sigma}^{+}>\lambda_{\Sigma}^{-}$, the $p$-value is 0.062 and we would reject the null at $10 \%$. This implies that there is some evidence for short-run amount asymmetry.

6. In the introduction we have indicated that OLS estimates are inefficient affecting the asymmetry tests. To illustrate this we have re-estimated the ECM using OLS. Again, adjustment symmetry is not rejected (the $p$-value drops from 0.972 to 0.906 ). The tests for short-run asymmetry, however, give different results. Now, the null of $\lambda_{i}^{+}=\lambda_{i}^{-} \forall i$ is not rejected ( $p$-value $\left.=0.312\right)$. Also the $p$-value of the test of $H_{0}$ : $\lambda_{\Sigma}^{+}=\lambda_{\Sigma}^{-} \mathrm{v} H_{1}: \lambda_{\Sigma}^{+} \neq \lambda_{\Sigma}^{-}$increases, from 0.124 to 0.744 . Neglecting volatility clustering turns the conclusions upside down: there is no evidence for timing or pattern asymmetry and the probability of incorrectly rejecting the null of short-run amount symmetry increases.

We characterize the adjustment path of the model by examining the cumulative adjustment function. It should be noted that this function is non-linear in the parameters, as the 
Figure 6: Cumulative adjustment in $P P_{t}$ after changes in the spot price $W P_{t}$

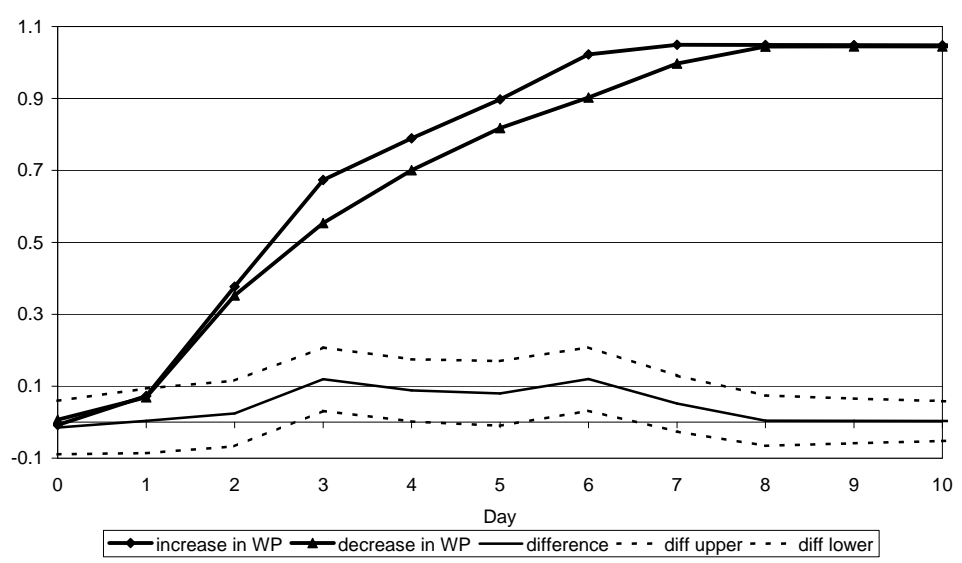

adjustment in the $i$-th period after a change in the spot price will be the sum of the estimated response parameters from Equation (2) and the error correction effects over $i$-th period. ${ }^{20}$ Figure 6 presents the calculated producer price response (in eurocents per litre) to a one-time one eurocent per litre increase or decrease in the spot price. To ease comparison we give the absolute value of the price responses. Also the difference between the two adjustment paths and its two standard error bounds are shown. ${ }^{21}$

The significant differences between the cumulative adjustment functions illustrate the finding of pattern asymmetry by the Wald-test. A one eurocent increase in the spot price leads to a 0.67 eurocents increase of the producer price after three days, whereas the estimated response to a one eurocent decrease is only 0.55 eurocents. This difference in the responses after three days is significant and remains (almost) significant for about four days. After six days the difference is no longer significant and the long-run equilibrium price is reached.

\footnotetext{
${ }^{20}$ The calculation of the cumulative adjustment function can be found in Borenstein et al. (1997, p.337).

${ }^{21}$ The standard errors are approximated using the Delta method (see Judge et al., 1985, p.205-207). In the calculation we consider the long run effect $\mu_{1}$ as predetermined.
} 


\section{Conclusions}

Analyzing high frequency data leads to a better understanding of the pricing process when upstream prices are volatile as others have argued. However, using high frequency data in OLS regressions leads to a loss of statistical efficiency if volatility is serially correlated over time. In this paper we take care of volatility clustering by estimating an EGARCH model. As a by-product we introduce a new type of asymmetry in the literature on asymmetric price adjustments, namely shock asymmetry: an unexpected increase in the producer price has a larger effect on the variance of the producer price than an unexpected drop in the producer price.

We conclude that an ECM is an appropriate way to model retail gasoline price changes. Cointegration leads us to conclude that there is no amount asymmetry in the long run. However, there is some evidence for short-run amount asymmetry. Also, there is a faster reaction to upward changes in spot prices than to downward changes in spot prices: 8 and 9 days, respectively. The parameters for upward changes are also significantly larger for the third lag. This implies timing or pattern asymmetry three days after the change in the spot price. 


\section{References}

Bachmeier, L.J. and J.M. Griffin (2003), "New evidence on asymmetric gasoline price responses", The Review of Economics and Statistics, 85(3), 772-776.

Bacon, R.W. (1991), "Rockets and feathers: The asymmetric speed of adjustment of UK retail gasoline prices to cost changes", Energy Economics, 13(3), 211-218.

Bettendorf, L., S.A. van der Geest, and M. Varkevisser (2003), "Price asymmetry in the Dutch retail gasoline market", Energy Economics, 26(6), 669-689.

Bollerslev, T., R.F. Engle, and D.B. Nelson (1994), "ARCH models", in R.F. Engle and D.L. McFadden, editors, Handbook of Econometrics, volume 4, North-Holland, Amsterdam, chapter 49, 2959-3038.

Borenstein, S., A.C. Cameron, and R. Gilbert (1997), "Do gasoline prices respond asymmetrically to crude oil price changes?", Quarterly Journal of Economics, 112(1), 305339.

Borenstein, S. and A. Shepard (2002), "Sticky prices, inventories, and market power in wholesale gasoline markets", RAND Journal of Economics, 33(1), 116-139.

Canoy, M. and S. Onderstal (2003), "Tight oligopolies: In search of proportionate remedies", CPB document 29, CPB Netherlands Bureau for Economic Policy Analysis, The Hague.

Castanias, R. and H. Johnson (1993), "Gas wars: Retail gasoline price fluctuations", The Review of Economics and Statistics, 75(1), 171-174.

Davis, M.C. and J.D. Hamilton (2004), "Why are prices sticky? The dynamics of wholesale gasoline prices", Journal of Money, Credit and Banking, 36(1), 17-37. 
Eckert, A. (2003), "Retail price cycles and the presence of small firms", International Journal of Industrial Organization, 21(2), 151-170.

Eckert, A. and D.S. West (2004), "Retail gasoline price cycles across spatially dispersed gasoline stations", Journal of Law and Economics, 47(1), 245-273.

Engle, R.F. (1982), "Autoregressive conditional heteroscedasticity with estimates of the variance of UK inflation", Econometrica, 50(4), 987-1007.

Engle, R.F. (2004), "Risk and volatility: Econometric models and financial practice", The American Economic Review, 94(3), 405-420.

Engle, R.F. and C.W.J. Granger (1987), "Cointegration and error-correction: Representation, estimation, and testing", Econometrica, 55(2), 251-276.

Engle, R.F. and S. Kozicki (1993), "Testing for common features", Journal of Business and Economic Statistics, 11(4), 369-380.

European Commission (1999), "Commission decision 0f 29.09.1999 declaring a concentration compatible with the common market and the EEA Agreement: case no. IV/M.1383Exxon/Mobil", C(1999)-3093, Brussels.

Gannon, G.L. (1996), "First and second order inefficiency in Australasian currency markets", Pacific-Basin Finance, 4(2-3), 315-327.

Geweke, J. (2004), "Issues in the "Rockets and Feathers" gasoline price literature", Report to Federal Trade Commission, University of Iowa.

Granger, C.W.J. and A.A. Weiss (1983), "Time series analysis of error-correction models", in S. Karlin, T. Amemiya, and L.A. Goodman, editors, Studies in Econometrics, Time Series and Multivariate Statistics, in Honor of T.W. Anderson, Academic Press, San 
Diego, 255-278.

Judge, G.G., W.E. Griffiths, R.C. Hill, H. Lütkepohl, and T.C. Lee (1985), The Theory and Practice of Econometrics, second edition, John Wiley and Sons, New York.

Lewis, M. (2003), "Asymmetric price adjustment and consumer search: An examination of the retail gasoline market", CSEM Working Paper 120.

MacKinnon, J.G. (1996), "Numerical distribution functions for unit root and cointegration tests", Journal of Applied Econometrics, 11(6), 601-618.

MacKinnon, J.G., A.A. Haug, and L. Michelis (1999), "Numerical distribution functions of likelihood ratio tests for cointegration", Journal of Applied Econometrics, 14(5), $563-577$.

Maskin, E. and J. Tirole (1988), "A theory of dynamic oligopoly II: Price competition, kinked demand curves, and Edgeworth cycles", Econometrica, 56(3), 571-599.

Nelson, D.B. (1991), "Conditional heteroscedasticity in asset returns: A new approach", Econometrica, 59(2), 347-370.

NMa (2001), "Oil companies keep prices artificially high through agreements with filling station owners", Netherlands Competition Authority Press Releases, No. 01/46, The Hague.

NMa (2003), "No prohibition on petrol support system - annual reporting on market trends", Netherlands Competition Authority Press Releases, No. 03/09, The Hague.

NMa (2004), "NMa on the petrol market: Increasing competition extends to the subsidiary road network", Netherlands Competition Authority Press Releases, No. 04/06, The Hague. 
Noel, M. (2004), "Edgeworth price cycles: Evidence from the Toronto retail gasoline market", Working Paper 2004-03, UCSD Department of Economics.

Phillips, P.C.B. and P. Perron (1988), "Testing for a unit root in time series regression", Biometrika, 75(2), 335-346.

Rahbek, A., E. Hansen, and J.G. Dennis (2002), "ARCH innovations and their impact on cointegration rank testing", Working Paper. 